\title{
Short segments of Barrett's epithelium and intestinal metaplasia in normal appearing oesophagogastric junctions: the same or two different entities?
}

\begin{abstract}
A Dias Pereira, A Suspiro, P Chaves, A Saraiva, L Glória, J C Mendes de Almeida,
\end{abstract} C N Leitão, J Soares, F C Mira

\begin{abstract}
Background-Endoscopic diagnosis of short segments of Barrett's epithelium (SSBE) is difficult and its meaning in terms of the presence of specialised columnar epithelium (SCE) has not been prospectively evaluated.
\end{abstract}

Aims-To evaluate the prevalence of SCE in patients with an endoscopic diagnosis of SSBE and in individuals with normal appearing oesophagogastric junctions, and to compare the clinical characteristics of these two groups.

Patients-Thirty one patients with an endoscopic diagnosis of short Barrett's oesophagus, less than $3 \mathrm{~cm}$ in length (group A), and 44 consecutive patients with normal appearing oesophagogastric junctions (group B).

Methods-Multiple biopsies were performed in suspicious epithelium and at the oesophagogastric junction in groups $A$ and $B$, respectively.

Results-Age and sex distribution were similar in both groups. Reflux symptoms were more frequent in group $A(p<0.001)$, as were endoscopic and histological signs of oesophagitis $(p<0.0001$ and $p=0.001$, respectively). SCE was found in $61.3 \%$ of group A patients compared with $25 \%$ in group $B(p<0.002)$, with men predominating in group $A$ while women were more frequent in group $B(p=0.02)$. The differences in reflux symptoms and endoscopic/ histological oesophagitis remained significant.

Conclusions-These results show that endoscopic diagnosis of SSBE is associated with a high prevalence of SCE, significantly higher than that found in normal appearing oesophagogastric junctions. Differences between patients with SCE in the two groups suggest they may represent two different entities.

(Gut 1998;42:659-662)

Keywords: Barrett oesophagus; short segments; endoscopic diagnosis

Barrett's oesophagus is a premalignant condition defined as the replacement of the normal distal oesophageal epithelium by specialised columnar epithelium (SCE), also known as intestinal type metaplasia. The reported preva- lence of Barrett's associated adenocarcinoma varies widely, with an average value of $10 \%{ }^{1}$ On the other hand, and for still unidentified reasons, the incidence of oesophageal adenocarcinoma has shown a rapid increase in the past few years, now accounting for approximately $50 \%$ of oesophageal cancers in the USA. $^{2-5}$

The classic definition of Barrett's oesophagus required the presence of at least $2-3 \mathrm{~cm}$ of metaplastic epithelium above the oesophagogastric junction. ${ }^{67}$ However, short segments of Barrett's epithelium, less than $3 \mathrm{~cm}$ in length, are being reported with an increased frequency and have been implicated as a risk factor for the development of adenocarcinoma of the cardia. ${ }^{8-12}$ Endoscopic diagnosis of this entity is difficult and always requires histological demonstration of SCE. Most endoscopists do not perform biopsies unless the mentioned extent of red mucosa is present, and so these short segments are frequently unrecognised.

Spechler et al recently described the presence of intestinal metaplasia in some normal appearing oesophagogastric junctions. ${ }^{13}$ The relation of this condition to short segment Barrett's oesophagus has not yet been investigated.

With the aim of evaluating the meaning of endoscopic diagnosis of short segment Barrett's oesophagus, we conducted a prospective study comparing patients with endoscopically diagnosed short segments of Barrett's epithelium (less than $3 \mathrm{~cm}$ ) and a group of consecutive individuals scheduled for upper endoscopy for other indications and considered by the endoscopist as having normal appearing oesophagogastric junctions.

\section{Patients and methods}

The study was approved by our institution's ethics committee and informed consent was obtained from all patients before entry. For the purposes of this study, Barrett's oesophagus was defined by the simultaneous presence of red velvet mucosa above the oesophagogastric junction and SCE. The sole presence of the former defined endoscopic Barrett's oesophagus.

\section{PATIENTS}

Thirty one patients with endoscopically appearing short segments of Barrett's oesophagus less than $3 \mathrm{~cm}$ long were included in the study (group A). These were consecutive patients selected from our outpatient clinic over a two 
Table 1 Clinical characteristics of patients in the two study groups according to the presence of specialised columnar epithelium (SCE)

\begin{tabular}{|c|c|c|c|c|c|c|c|c|c|c|c|c|c|}
\hline & \multirow[b]{2}{*}{$\begin{array}{l}\text { Sex } \\
(M / F)\end{array}$} & \multirow[b]{2}{*}{$\operatorname{Age}(y)^{*}$} & \multirow[b]{2}{*}{$\begin{array}{l}\text { Duration } \\
\text { of GOR } \\
\text { symptoms * }\end{array}$} & \multicolumn{2}{|c|}{ GOR symptoms } & \multicolumn{4}{|c|}{ Endoscopic oesophagitis } & \multicolumn{2}{|c|}{$\begin{array}{l}\text { Histological } \\
\text { oesophagitis }\end{array}$} & \multicolumn{2}{|c|}{ Hiatus hernia } \\
\hline & & & & Yes & No & None & $\begin{array}{l}\text { Grade } \\
1-2\end{array}$ & $\begin{array}{l}\text { Grade } \\
3-4\end{array}$ & $\begin{array}{l}\text { Overall } \\
\text { frequency }\end{array}$ & Yes & No & Yes & No \\
\hline \multicolumn{14}{|l|}{ Group $A(n=31)$} \\
\hline $\mathrm{SCE}+(\mathrm{n}=19)$ & $14 / 5$ & $58.9(13.1)$ & $17.5(5.0)$ & $14(74)$ & $5(26)$ & $5(26)$ & $10(53)$ & $4(21)$ & $14(74)$ & $13(68)$ & $6(32)$ & $10(53)$ & $7(37)$ \\
\hline $\begin{array}{l}\text { SCE- }(n=12) \\
\text { Group } B(n=44)\end{array}$ & $6 / 6$ & & & $10(83)$ & $2(17)$ & $7(58)$ & $5(42)$ & 0 & $5(42)$ & $8(67)$ & $4(33)$ & $10(83)$ & $2(17)$ \\
\hline $\mathrm{SCE}+(\mathrm{n}=11)$ & $3 / 8$ & $60.2(14.2)$ & $10.9(8.9)$ & $2(18)$ & $9(82)$ & $10(91)$ & $1(8)$ & 0 & $1(8)$ & $2(18)$ & $9(82)$ & $2(18)$ & $9(82)$ \\
\hline SCE- $(n=33)$ & $16 / 17$ & & & $12(36)$ & $21(64)$ & $24(73)$ & $5(15)$ & $4(12)$ & $9(27)$ & $8(24)$ & $25(76)$ & $14(42)$ & 19(58) \\
\hline
\end{tabular}

^Expressed as mean (SD). All other data are expressed as number (\%).

GOR, gastro-oesophageal reflux.

year period, on the basis of endoscopic suspicion of short segment Barrett's oesophagus. According to Spechler et al, ${ }^{13}$ the oesophagogastric junction was defined as follows: in the absence of a hiatus hernia, as the point of diaphragmatic indentation; or in the presence of a hiatus hernia, as the point where proximal gastric folds taper off. We considered two endoscopic features of the squamocolumnar transition as suspicious of short segment Barrett's oesophagus: a straight and regular $\mathrm{Z}$ line displaced upwards in relation to the gastro-oesophageal junction by less than $3 \mathrm{~cm}$ (circumferential type); and an irregular $\mathrm{Z}$ line, with eccentric tongues of red mucosa extending above this junction (digitated type). The extent of the short Barrett segment was measured between the junction and the most proximal extension of gastric type mucosa. Endoscopic distances were measured in $\mathrm{cm}$ from the incisor teeth.

Group B consisted of 44 adult ambulatory consecutive patients who underwent upper endoscopy in our endoscopy unit for any reason and were considered by the endoscopist as having a normal appearing oesophagogastric junction. Patients with a history of cancer or prior gastric/oesophageal surgery were excluded, as were those unable to give informed consent or with any contraindication to performance of endoscopic biopsies. Primary indications for upper endoscopy in this group were: reflux symptoms $(n=14)$, other dyspeptic symptoms $(n=18)$, evaluation of iron deficient anaemia $(n=3)$, chronic diarrhoea $(n=2)$, and miscellaneous $(n=7)$.

All patients included in this study were questioned about symptoms of gastro-oesophageal reflux (heartburn, regurgitation, dysphasia, and odynophagia). Endoscopic signs of oesophagitis were recorded and graded according to the Savary-Miller classification. ${ }^{14}$ The presence of Barrett's oesophagus was not considered for the purposes of this study as evidence of grade IV oesophagitis.

BIOPSY PROTOCOL

In group $A$, multiple biopsy samples (minimum of four) were obtained from the entire length of the suspected short Barrett segment. In group $\mathrm{B}$, we took samples from the four quadrants of the normal appearing oesophagogastric junction, just below the squamocolumnar junction ( $\mathrm{Z}$ line). For both groups, one biopsy from squamous epithelium approxi- mately $3 \mathrm{~cm}$ above the $\mathrm{Z}$ line was performed to detect histological signs of oesophagitis.

\section{HISTOLOGY}

Formalin fixed, paraffin wax embedded samples from all biopsy specimens were stained with haematoxylin and eosin. Periodic acid Schiff-alcian blue (PAS/AB; $\mathrm{pH} 2.5$ ) was used to show the presence of acid mucins. The diagnosis of Barrett's oesophagus was made in the presence of specialised columnar epithelium, defined by the unequivocal demonstration of intestinal type goblet cells.

Reflux oesophagitis and dysplasia were classified according to the criteria of Ismail-Beiji et $a l^{15}$ and Riddell et $a l,{ }^{16}$ respectively.

\section{STATISTICAL METHODS}

Differences between groups were tested using the $\chi^{2}$ and Fisher exact tests. The significance level was set at $5 \%$.

\section{Results}

Table 1 presents clinical characteristics of all patients included in the study. Age distribution was similar in both groups. Women were more prevalent in group B although not significantly so $(p=0.10)$. The prevalence of gastrooesophageal reflux symptoms was higher in group A patients $(\mathrm{p}<0.001)$ as was endoscopic and histological evidence of oesophagitis $(p<0.0001$ and $p=0.001$, respectively). Similarly, the presence of a hiatus hernia was more frequent in group $\mathrm{A}(\mathrm{p}<0.001)$. In group $\mathrm{A}$, the extent of suspicious mucosa was $1 \mathrm{~cm}$ or less in 17 patients, between 1 and $2 \mathrm{~cm}$ in four patients, and $2 \mathrm{~cm}$ or more in 10 patients; the squamocolumnar transition was of circumferential type in 15 cases and digitated in the remaining 16 .

SCE was found in $61.3 \%(19 / 31)$ of patients with endoscopic short Barrett segments (group A) and in $25 \%(11 / 44)$ of patients with normal appearing junctions (group B) $(p<0.002)$. Furthermore, the prevalence of SCE in Barrett looking tongues of $1 \mathrm{~cm}$ or less was $47 \%(8 / 17)$, higher than that found in normal appearing junctions (25\%). In endoscopic Barrett segments longer than $1 \mathrm{~cm}, \mathrm{SCE}$ was found in $79 \%$ of cases. This prevalence was similar irrespective of the type of the squamocolumnar junction.

When patients with SCE were considered separately within each group (table 1), there was a significant difference in sex distribution: in group A there was a strong male predomi- 


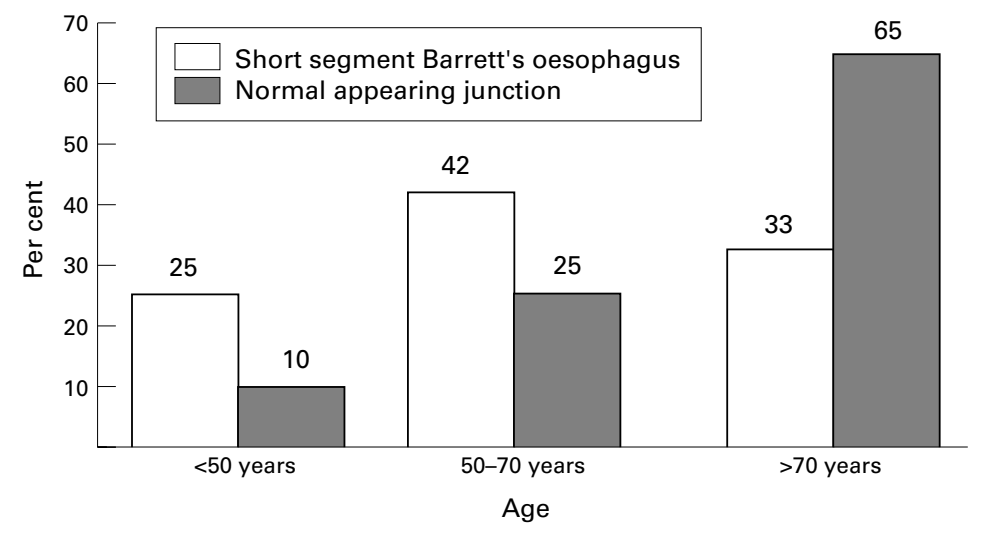

Figure 1 Percentage of patients with SCE in the two study groups according to age.

nance (14:5) whereas in group B there was a female preponderance $(8: 3) \quad(p=0.02)$. In group A patients the prevalence of SCE was similar in different age groups, whereas in group B this prevalence increased steadily with advancing age, although the differences between the age groups did not reach statistical significance (fig 1). The aforementioned differences in the prevalence of reflux symptoms, oesophagitis, and presence of hiatus hernia remain significant even when considering patients with SCE only $(p=0.003, p=0.001$, and $\mathrm{p}=0.005$, respectively).

We found no dysplasia or cancer in any of the biopsy specimens from either group.

\section{Discussion}

Barrett's oesophagus is undoubtedly a highly prevalent condition, although frequently unrecognised. ${ }^{17-20}$ Endoscopic criteria for its identification have changed dramatically over the past few years with the description of short segments of SCE and the recognition of its clinical importance as a precursor of oesophageal and cardia adenocarcinoma. ${ }^{8-10}$ At the present time, the presence of goblet cells (SCE) anywhere within the oesophagus supports the diagnosis of Barrett's oesophagus. However, if long segments of Barrett's epithelium, $3 \mathrm{~cm}$ or more, fitting the classic diagnostic criteria, are easily recognised, the identification of shorter segments is not so straightforward. The ability of the endoscopist to distinguish abnormal tiny tongues of red mucosa extending above the gastro-oesophageal junction from a normal but irregular appearing squamocolumnar junction has not been prospectively evaluated. The results of two recent reports ${ }^{21}{ }^{22}$ illustrate this problem well: in two populations of individuals with endoscopic suspicion of short segment Barrett's oesophagus, biopsy samples showed SCE in only $37 \%$ and $48 \%$ of cases respectively. Whether this frequency of SCE is significantly different from the one found in normal appearing junctions is still an unanswered question.

Our study supports the value of endoscopic recognition of even very short tongues of Barrett's oesophagus. This recognition was associated with a high prevalence of SCE, significantly higher than that for junctions considered to be normal. Failure of the endoscopist to rec- ognise and sample these short tongues is undoubtedly an important factor leading to underestimation of the true prevalence of Barrett's oesophagus. Moreover, the reported association of these short segments with dysplasia and adenocarcinoma argues in favour of systematically performing biopsies on all abnormal appearing junctions.

The high prevalence of SCE in patients with endoscopic suspicion of short segment Barrett's oesophagus found in our study is in contrast with previous reports. ${ }^{21} 22$ One possible explanation for this observation was the enrolment of a higher risk population: $77 \%$ of our patients presented reflux symptoms, compared with $50 \%$ and $58 \%$ in the aforementioned studies. The prospective nature of this study and the fact that all endoscopic diagnoses of short segment Barrett's oesophagus were made by a single and experienced endoscopist with a high index of suspicion for this condition, are additional features that could have had contributed to this.

Additionally and as suggested by a previous report in abstract form, ${ }^{23}$ we also found a positive association between the frequency of SCE and the extent of red mucosa above the gastrooesophageal junction: the longer the extent of red mucosa, the higher the frequency of SCE.

There were significant differences in terms of demographic distribution between patients with SCE in the two study groups. Patients with short segment Barrett's oesophagus had a higher male:female ratio (2.8:1), similar to the one described in classic long segment Barrett's oesophagus, ${ }^{36724}$ and presented with a higher frequency of indicators of gastro-oesophageal reflux (reflux symptoms and endoscopic or histological signs of oesophagitis) and a hiatus hernia. This is consistent with the most accepted theory, which considers Barrett's oesophagus to be a condition acquired as a result of chronic gastro-oesophageal reflux, ${ }^{725-27}$ and is supported by the results of a recently published study ${ }^{28}$ which shows a very high prevalence of short segment Barrett's oesophagus in reflux patients.

As opposed to patients with short segments of Barrett's oesophagus, individuals with SCE at normal appearing junctions were predominantly female and had a lower frequency of reflux indicators, in agreement with the results of one previous report. ${ }^{11}$ A very recent report ${ }^{29}$ suggests a correlation between intestinal metaplasia at normal junctions and reflux symptoms, but the authors do not adequately distinguish completely normal junctions from very short segment Barrett's oesophagus of less than $2 \mathrm{~cm}$. Another recent and very interesting report suggests that intestinal metaplasia of the gastric cardia may be related to Helicobacter pylori infection, ${ }^{30}$ adding further support to the idea that this entity and short segment Barrett's oesophagus may indeed be different conditions.

These differences between the two groups of patients with SCE argue against short segment Barrett's oesophagus being the result of upwards extension of intestinal metaplasia at the gastric cardia mucosa. This is corroborated by a recent study ${ }^{22}$ which investigated the 
prevalence of intestinal metaplasia of the stomach in patients with an endoscopic diagnosis of short segment Barrett's oesophagus. The prevalence of gastric intestinal metaplasia was similar in patients with or without SCE in biopsy specimens from endoscopic short segment Barrett's oesophagus.

The prevalence of SCE at normal appearing junctions found in our study $(25 \%)$ is similar to the $18 \%$ level described in a previous similar report. ${ }^{13}$ The slight difference may be related to the greater mean age of our patients ( 60 versus 53 years), as our data suggest that the prevalence of SCE at normal appearing junctions increases with advancing age.

Previous studies, relating to classic long segment Barrett's oesophagus, reported an increased prevalence with advancing age, with no increase in mean extension. ${ }^{6}$ There are no similar studies dealing with short segment Barrett's oesophagus, but in the present study, no difference was found in the prevalence of SCE between different age groups. However, the small number of patients without SCE precludes any definitive conclusions and future studies including a larger number of patients are awaited.

In conclusion, our study supports the notion that endoscopic recognition of abnormally appearing oesophagogastric junctions is a strong predictor of short segment Barrett's oesophagus. The epidemiological differences between patients with SCE in short segment Barrett's oesophagus and in normal appearing junctions suggest that the latter condition may not be simply a very short segment Barrett's oesophagus. The very high frequency of reflux manifestations in patients with short segment Barrett's oesophagus, compared with that found in individuals with normal appearing junctions, supports an aetiological role of gastro-oesophageal reflux in this condition, as accepted for long segment Barrett's oesophagus. According to our data, intestinal metaplasia at normal junctions seems to be a condition more frequent in women, increasing in frequency with advancing age, and less related to gastro-oesophageal reflux. Larger prospective studies including functional evaluation are necessary to address this issue and to clarify the relation between the latter condition, gastrooesophageal reflux, and $H$ pylori infection.

This work was supported by the Comissão de Fomento da This work was supported by the Comissão de Fomento da We thank Marilia Cravo for reviewing the manuscript.

1 Spechler SJ, Goyal RK. Barrett's oesophagus. N Engl f Med 1986;315:362-71.

2 Blot WJ, Devesa SS, Kneller RW, et al. Rising incidence of adenocarcinoma of the esophagus and gastric cardia. adenocarcinoma of the

3 Blot WJ, Devesa SS, Fraumeni JF. Continuing climb in rates of esophageal adenocarcinoma: an update [letter]. $\mathscr{f} A M A$ 1993;270:1320.
4 Powell J, McConkey M. Increasing incidence of adenocarcinoma of the gastric cardia and adjacent sites. $\mathrm{Br} \mathcal{F}$ Cancer 1990;62:440-3.

5 Yang PC, Davis S. Incidence of cancer of the esophagus in the US by histologic site. Cancer 1988;61:612-17.

6 Cameron AJ, Lomboy CT. Barrett's esophagus: age, prevalence and extent of columnar epithelium. Gastroenterology 1992;103:1241-5.

7 Skinner DB, Walther BC, Riddell RH, et al. Barrett's esophagus. Comparison of benign and malignant cases. Ann Surg 1983;198:554-66.

8 Cameron AJ, Lomboy CT, Pera M, et al. Adenocarcinoma of the esophagogastric junction and Barrett's esophagus. Gastroenterology 1995;109:1541-6.

9 Clark GWB, Smyrk TC, Burdeles P, et al. Is Barrett's metaplasia the source of adenocarcinomas of the cardia? Arch Surg 1994;129:609-14.

10 Schnell TG, Sontag SJ, Chejfec G. Adenocarcinomas arising in tongues or short segments of Barrett's esophagus. Dig Dis Sci 1992;37:137-43.

11 Kalish RJ, Clancy PE, Orrenger MB, et al. Clinical, epidemiologic and morphologic comparison between adenocarcinomas arising in Barrett's esophageal mucosa and in the gastric cardia. Gastroenterology 1984;86:461-7.

12 MacDonald WC. Clinical and pathologic features of adenocarcinoma of the gastric cardia. Cancer 1972;29:724-32.

13 Spechler SJ, Zeroogian JM, Antonioli DA, et al. Prevalence of metaplasia at the gastroesophageal junction. Lancet 1994;344:1533-6.

14 Savary M, Miller G. The esophagus-handbook and atlas of endoscopy. Solothurn, Switzerland: Gassman Verlag AG, 1978.

15 Ismail-Beigi F, Huton PF, Poje CE. Histological consequences of gastroesophageal reflux in man. Gastroenterology 1970;58:163-74.

16 Riddell RH, Goldman H, Ransohoff DF, et al. Dysplasia in inflammatory bowel disease: standardised classification with provisional clinical implications. Hum Pathol 1983;14: 931-68.

17 Cameron AJ, Zinmeister AR, Ballard DJ, et al. Prevalence of columnar-lined (Barrett's) esophagus. Comparison of population-based clinical and autopsy findings. Gastroenterology 1990;99:918-22.

18 Hamilton SR, Smith RRL, Cameron JL. Prevalence and characteristics of Barrett's esophagus in patients with adenocarcinoma of the esophagus or esophagogastric junction. Hum Pathol 1988;19:942-8.

19 Sanfey H, Hamilton SR, Smith RRL, et al. Carcinoma arising in Barrett esophagus. Surg Gynecol Obstet 1985;161: $570-4$

20 Sarr MG, Hamilton SR, Marrone GC, et al. Barrett's esophagus: its prevalence and association with adenocarcinoma in patients with symptoms of gastroesophageal reflux. Am $\mathcal{F}$ Surg 1985;149:187-93.

21 Cameron AJ, Kamath PS, Carpenter HC. Barrett's esophagus; the prevalence of short and long segments in reflux patients [abstract]. Gastroenterology 1996;108:A65.

22 Weston AO, Krmpotich P, Makdisi WF, et al. Short segment Barrett's esophagus: clinical and histological features, associated endoscopic findings and association with gastric intestinal metaplasia. Am f Gastroenterol 1996;91:981-6.

23 Spechler SJ, Zeroogian JM, Wang HH, et al. The frequency of specialized intestinal metaplasia at the squamocolumnar junction varies with the extent of columnar epithelium lining the esophagus [abstract]. Gastroenterology 1995;108: A224.

24 Streitz JM, Ellis FH, Gibb SP, et al. Adenocarcinoma in Barrett's esophagus. Ann Surg 1991;213:122-5.

25 Iascone C, DeMeester TR, Little AG, et al. Barrett's esophagus. Functional assessment, proposed pathogenesis and surgical therapy. Arch Surg 1983;118:543-9.

26 Gillen P, Keeling P, Byrne PJ, et al. Barrett's esophagus: $\mathrm{pH}$ profile. Br f Surg 1987;74:774-6.

27 Winters C, Spurling TJ, Chobanian SJ, et al. Barrett's esophagus. A prevalent, occult complication of gastro-

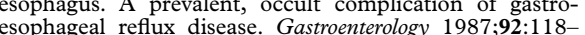
24.

28 Cameron AJ, Kamath PS, Carpenter HC. Barrett's esophagus. The prevalence of short and long segments in reflux patients [abstract]. Gastroenterology 1995;108:A65.

29 Johnston $\mathrm{MH}$, Hammond AS, Laskin W, et al. The prevalence and clinical characteristics of short segments of specialized intestinal metaplasia in the distal esophagus on routine endoscopy. Am f Gastroenterol 1996;91:1507-11.

30 Morales TG, Sampliner RE, Bhattacharyya A. Intestinal metaplasia of the gastric cardia. Am F Gastroenterol 1997; 92:414-18. 